\title{
Oxidative stress actuated by cellulose nanocrystals and nanofibrils in aquatic organisms of different trophic levels
}

\author{
Zhuang Wang ${ }^{\mathrm{a}, *}$, Lan Song ${ }^{\mathrm{b}, \mathrm{c}, * *}$, Nan Ye ${ }^{\mathrm{a}}$, Qi Yu ${ }^{\mathrm{d}}$, Yujia Zhai ${ }^{\mathrm{d}}$, Fan Zhang ${ }^{\mathrm{a}}$, Martina G. Vijver ${ }^{\mathrm{d}}$, \\ Willie J.G.M. Peijnenburg ${ }^{\mathrm{d}, \mathrm{e}}$ \\ ${ }^{a}$ School of Environmental Science and Engineering, Collaborative Innovation Center of Atmospheric Environment and Equipment Technology, Jiangsu Key Laboratory of \\ Atmospheric Environment Monitoring and Pollution Control, Nanjing University of Information Science and Technology, Nanjing 210044, PR China \\ ${ }^{\mathrm{b}}$ State Environmental Protection Key Laboratory of Integrated Surface Water-Groundwater Pollution Control, School of Environmental Science and Engineering, Southern \\ University of Science and Technology, Shenzhen 518055, PR China \\ ${ }^{\mathrm{c}}$ Shenzhen Institute of Sustainable Development, Shenzhen 518055, PR China \\ ${ }^{\mathrm{d}}$ Institute of Environmental Sciences (CML), Leiden University, Leiden 2300 RA, the Netherlands \\ ${ }^{\mathrm{e}}$ National Institute of Public Health and the Environment (RIVM), Center for the Safety of Substances and Products, Bilthoven 3720 BA, the Netherlands
}

\section{A R T I C L E I N F O}

\section{Keywords:}

Cellulose nanocrystals

Cellulose nanofibrils

Carbon-based polymers

Aquatic toxicity

Oxidative stress

\begin{abstract}
A B S T R A C T
Nanocellulose is a functional material derived from natural carbon-based polymers. These nanomaterials are biodegradable and renewable in nature and hence are seen as environmentally-friendly materials in many applications. The use of such innovative materials is accelerating and inescapable there is a need to test these presumed environmentally-friendly materials with regard to their ecotoxicity. Here, the acute toxicity and the oxidative stress of nanocelluloses as induced to three aquatic organisms of different trophic levels, namely Scenedesmus obliquus, Daphnia magna, and Danio rerio, were studied in relation to the composition and morphology of the celluloses. Wood-based cellulose nanocrystals (CNCs), cotton-based CNCs, and cotton-based cellulose nanofibrils were selected as model compounds. The results clearly demonstrated a lack of impact of the different nanocellulose materials on apical endpoints like growth inhibition and mortality after short-term exposure. The nanocellulose materials did activate oxidative stress as evoked by reactive oxygen species in the three aquatic organisms. Key factors ascertained to induce the oxidative stress were the composition and morphology. The nanocellulose induced oxidative stress was observed for all the species at concentrations higher than $0.01 \mathrm{mg} / \mathrm{L}$. This finding suggests a more general revelation of oxidative stress being a characteristic mechanism for nanocellulose toxicity to aquatic organisms.
\end{abstract}

\section{Introduction}

Cellulose is a major component of plant cell walls and the most abundant biopolymer on earth (Klemm et al., 2011). Nanocellulose defined as nano-structured cellulose has at least one dimension $<100$ nm (de Figueirêdo et al., 2012; Trache et al., 2017). It is categorized into two main types, namely cellulose nanocrystals (CNCs) and cellulose nanofibrils (CNFs) (Islam et al., 2014; Kargarzadeh et al., 2018). In recent years, nanocellulose attracted increasing attention because of its remarkable strength and physicochemical properties, e.g., high surfaceto-volume ratio, tailorable barrier properties, and superior tensile strength (Deepa et al., 2011; Eichhorn et al., 2010). Its unique properties and future commercialization prospects have resulted in several potential applications (Hemraz et al., 2015). Because nanocellulose materials are primarily obtained from naturally occurring sources, they are seen as environmentally-friendly, biocompatible, and safe. Sewage systems and municipal wastewater treatment plants are identified to become important intermediate pathways for nanocellulose transfer into the environment (Antonkiewicz et al., 2019). This assumption, that is not supported by solid scientific evidence, as well as their ever-increasing usage for many synthesized products, make that there is an urgent need to verify the safety claim as well as to gain insights in the (unwarranted) toxicity potentials of nanocellulose (Du et al., 2015; Farcas et al., 2016; Yanamala et al., 2014).

To date, limited data are available exemplifying the ecotoxicity and the mechanisms of toxicity elicited by nanocellulose. The few available

\footnotetext{
* Corresponding author.

** Correspondence to: L. Song, State Environmental Protection Key Laboratory of Integrated Surface Water-Groundwater Pollution Control, School of Environmental Science and Engineering, Southern University of Science and Technology, Shenzhen 518055, PR China.

E-mail addresses: zhuang.wang@nuist.edu.cn (Z. Wang), songl@sustech.edu.cn (L. Song).
} 
toxicity data are yet inconclusive. For instance, Du et al. (2015) indicated that nanocellulose exposure induced an increase in cytotoxicity to Escherichia coli $652 \mathrm{~T} 7$ as CNC exposure times increased, and elevated dispersibility of the CNCs was shown to increase their cytotoxicity. Vartiainen et al. (2011) detected acute toxicity of microfibrillated cellulose referred to as nanocellulose only at a very high level $(300 \mathrm{mg} / \mathrm{L})$ to Vibrio fischeri, and detected decrease in Daphnia magna movement induced by the microfibrillated cellulose. Ogonowski et al. (2018) also concluded that CNFs display a low toxic potential to filter-feeding organism (D. magna). In addition, Salehpour et al. (2018) found that the nanocomposites of polyvinyl alcohol and CNFs did not generate any negative effects on plants including cress and spinach.

Oxidative stress as a common mechanism underlying carbon-based nanoparticle-induced toxicity to different aquatic organisms has been proposed (Freixa et al., 2018; De Marchi et al., 2018). A clear indication of oxidative stress in the marine alga chlorophyte Dunaliella tertiolecta was observed for single-walled (SWNTs) (Thakkar et al., 2016) and multi-walled (MWNTs) carbon nanotubes (Wei et al., 2010). Exposure to PEGylated SWNTs can lead to toxic effects on zebrafish embryos with an increase of the production of reactive oxygen species (ROS) (Cordeiro et al., 2018). MWNTs caused oxidative stress after subchronic exposure of two fish species (Danio rerio and Astyanax altiparanae) as shown by monitoring the activity of superoxide dismutase (SOD) and catalase (CAT) (Cimbaluk et al., 2018). Consequently, it is speculated that nanocellulose causes similar oxidative stress effects as carbon nanotubes, thus posing a potential negative impact on ecological species.

In order to enrich the data in evaluating the ecotoxicity of nanocellulose and to better understand the potential mechanisms of toxicity, the present study assessed the impacts of CNC- and CNF-exposure on an alga species (Scenedesmus obliquus), a cladoceran species ( $D$. magna), and a freshwater fish larva ( $D$. rerio) as aquatic model organisms, representing three different trophic levels. Often three different trophic levels are the base set to derive effect assessment (according OECD regulation). Within the selection of assessment factors to derive predicted no effect concentrations as done for risk assessment, also this base set is used in which a fish, zooplankton and algae species is tested for its acute effect concentration. Here we determined a new material of which the mode-of-action is not well-known, hence we selected accordingly three species of different trophic levels being non-related respecting ecophysiology. Moreover, it is known that the toxicity and uptake of nanomaterials depend on the biological species (see for instance Chen et al., 2018; Ivask et al., 2014). Furthermore, we applied a battery of ecotoxicological endpoints spanning molecular toxicology, oxidative stress, antioxidant capacity, and apical endpoints such as growth and survival, over a wide range of exposure concentrations.

\section{Materials and methods}

\subsection{Test materials and media}

Wood-based CNCs (WCNCs) with a nominal diameter of 4-10 nm and length of $100-500 \mathrm{~nm}$ in a colloid suspension (3.5 wt\%), cottonbased CNCs (CCNCs) with a nominal diameter of 4-10 nm and length of $100-500 \mathrm{~nm}$ in a colloid suspension (7.1 wt\%), and cotton-based CNFs (CCNFs) with a nominal diameter of 4-10 nm and length of $1000-3000 \mathrm{~nm}$ in a colloidal suspension $(1.1 \mathrm{wt} \%)$ were kindly provided from Qihong Technology Co., Ltd. (Guilin, China).

The algae medium $(\mathrm{pH} 7.8 \pm 0.2)$ prepared according to OECD guidelines (OECD 201, 2006) was used as culture and test medium for both $S$. obliquus and D. magna. The embryo medium (pH 7.0-8.0) used as culture and test medium for zebrafish embryo contained: $\mathrm{NaCl}$ $5.03 \mathrm{mM}$; KCl $0.17 \mathrm{mM} ; \mathrm{CaCl}_{2} \cdot 2 \mathrm{H}_{2} \mathrm{O} 0.33 \mathrm{mM}$; $\mathrm{MgSO}_{4} \cdot 7 \mathrm{H}_{2} \mathrm{O} 0.33 \mathrm{mM}$; Methylene blue $0.1 \%(\mathrm{w} / \mathrm{v})$.

\subsection{Test suspensions and concentrations}

Stock suspensions of $100 \mathrm{mg} / \mathrm{L}$ of the nanocelluloses were prepared freshly by dispersing the colloidal suspension into the test media. The suspensions were subsequently sonicated for $30 \mathrm{~min}$ in a water-bath sonicator (KH-3200DE, $150 \mathrm{~W}$ at $100 \%$ energy input). The stock suspensions were diluted to the desired exposure concentrations, ranging from 0.01 to $10 \mathrm{mg} / \mathrm{L}$ for the toxicity tests.

\subsection{Physicochemical analyses}

The surface chemistry of the nanocelluloses was characterized by Xray Photoelectron Spectroscopy (XPS, Thermo Scientific ESCALAB 250Xi, USA) and Fourier Transform Infrared Spectroscopy (FTIR, Spectrum 100, Perkin Elmer, Inc., USA). A transmission electron microscope (TEM, FEI-Tecnai G2F20, Hillsboro, OR, USA) was used to characterize the morphology of the nanocelluloses in the colloid suspension and two types of test media. The zeta potential and the hydrodynamic diameter of the three types of nanocelluloses suspensions were analyzed at 0,48 , and $96 \mathrm{~h}$ after incubation under the same conditions as in the toxicity tests, by utilizing a ZetaSizer instrument (Nano ZS90, Malvern Instruments Ltd., Worcestershire, UK). The three types of nanocelluloses were suspended for the TEM, zeta potential and hydrodynamic diameter measurements at a concentration of $10 \mathrm{mg} / \mathrm{L}$ to the two types of test media, which represent the highest exposure concentration in the toxicity testing.

\subsection{Test species and acute toxicity tests}

The algal species $S$. obliquus was obtained from the Chinese Academy of Sciences, Institute of Hydrobiology (Wuhan, China) and incubated under a 12:12 h light (3000-4000 lx)/dark photoperiod $\left(24 \pm 1{ }^{\circ} \mathrm{C}\right)$. The algae suspension was shaken by hand three times a day to prevent cell adhesion until it reached the logarithmic growth phase for acute toxicity tests $(96 \mathrm{~h})$. Daphnids were cultured in clean tap water in an incubator under a 16:8 h light/dark photoperiod $\left(23 \pm 1{ }^{\circ} \mathrm{C}\right)$ and fed on $S$. obliquus. After over two-week-old daphnids began to steadily produce a large number of neonates, the newborn neonates $(<24 \mathrm{~h}$ old) were kept into algae medium for $1 \mathrm{~h}$, and used for toxicity testing $(48 \mathrm{~h})$ and oxidative stress analysis. $D$. rerio wildtype strain $\mathrm{AB}$ embryos were obtained from Eze-Rinka (Nanjing, China). Embryos incubated at $26 \pm 1{ }^{\circ} \mathrm{C}$ within the 4- to 32-cell stage were selected for testing ( $96 \mathrm{~h}$ ).

The acute toxicity tests were performed according to the OECD guidelines (OECD 201 (2006) for S. obliquus, OECD 202 (2004) for D. magna, and OECD 236 (2013) for D. rerio) with minor modifications: (1) the initial cellular density and exposure time were set at $3 \times 10^{5}$ cells/ $\mathrm{mL}$ and $96 \mathrm{~h}$; (2) 10 daphnids were transferred into a test vial containing either $50 \mathrm{~mL}$ of the test suspensions or control, each exposure concentration was tested using the same batch of daphnids with three parallels; (3) 12 zebrafish embryos were exposed to each test suspension on a single plate and testing was performed in two independent experiments.

\subsection{Oxidative stress and anti-oxidative assays}

2',7'-Dichlorodihydrofluorescein diacetate (DCFH-DA), purchased from Macklin Biochemical Co., Ltd. (Shanghai, China), was used as a fluorescent probe to measure the intracellular ROS level. The ROS analysis and tracking for all test species of different trophic levels were performed following the procedures described previously (Ghobadian et al., 2015; Hu et al., 2015; Xie et al., 2006) with slight modifications. Briefly, the algal cells ( $96 \mathrm{~h}$ ), the daphnids (48 h), and the zebrafish larvae $(96 \mathrm{~h})$ were collected at the end of each time interval. Then the DCFH-DA (10 $\mu \mathrm{M}$ for algal cells and daphnids, as well as $20 \mu \mathrm{M}$ for zebrafish larvae) was incubated for $30 \mathrm{~min}$ for algal cells and daphnids, 
and for $60 \mathrm{~min}$ for zebrafish larvae. The samples were washed three times with culture media under the same conditions for fluorescence intensity (FI) detection and for ROS tracking using a fluorescence spectrophotometer (F96PRO, Shanghai Kingdak Scientific Instrument Co., Ltd., Zhejiang, China) and a fluorescent microscope OLYMPUS BX51 (Olympus Corp., Tokyo, Japan) with an excitation wavelength of $485 \mathrm{~nm}$ and an emission wavelength of $530 \mathrm{~nm}$, respectively. The relative ROS level was calculated as a percentage (\%) according to the equation:

$\%$ Relative ROS level $=\left[\right.$ mean $F_{t} /$ mean $\left.F_{c}\right] \times 100$

where $F_{\mathrm{t}}$ indicates the fluorescence of the treated groups; $F_{\mathrm{c}}$ equals the fluorescence of the control groups.

Total anti-oxidative capacity $\left(\mathrm{TAC}_{\mathrm{SM}}\right.$; the contribution of small molecules to the antioxidant defense of the organism) testing was determined using the appropriate commercial kits, which were purchased from Nanjing Institute of Jiancheng Biological Engineering (Nanjing, China). The specific tests were completed according to the manufacturer's instructions (Wang et al., 2017).

\subsection{Statistical analysis}

All data are presented as means \pm standard deviation (SD). Statistically significant differences between groups were determined by means of a $t$-test at significance levels of $p<0.05, p<0.01$, and $p<0.001$.

\section{Results and discussion}

\subsection{Physicochemical characterization of nanocelluloses}

The XPS measurement (Fig. S1) showed that the WCNC, CCNC, and CNF surfaces consisted of $40.74 \% \mathrm{C} / 40.73 \% \mathrm{O} / 12.33 \% \mathrm{Na} / 0.69 \% \mathrm{~N} /$ $5.51 \% \mathrm{~S}, 61.59 \% \mathrm{C} / 36.69 \% \mathrm{O} / 0.57 \% \mathrm{Na} / 0.62 \% \mathrm{~N} / 0.54 \% \mathrm{~S}$, and $53.72 \% \mathrm{C} / 34.76 \% \mathrm{O} / 6.72 \% \mathrm{Na} / 0.72 \% \mathrm{~N} / 4.08 \% \mathrm{~S}$, respectively. The FTIR spectrum indicated that the nanocelluloses used contained plentiful O-containing functionalities, e.g., $-\mathrm{OH}$ and $-\mathrm{COOH}$, as depicted in Fig. S2.

TEM images of the colloidal suspensions of WCNC, CCNC, and CCNF and their suspensions at the concentration of $10 \mathrm{mg} / \mathrm{L}$ in the algae and the embryo medium are presented in Fig. 1A-I. In the colloidal suspensions, individual nanocelluloses are visible and well-distributed throughout the samples (Fig. 1A-C). In the test media, WCNCs (Fig. 1D and G) and CCNFs (Fig. 1F and I) exhibited a needle-like rigid structure with smooth edges while CCNCs (Fig. $1 \mathrm{E}$ and $\mathrm{H}$ ) with a few forks. The length of the nanocelluloses increased in the order of CCNCs < WCNCs < CCNFs, as estimated on the basis of the TEM pictures.

The zeta potential and hydrodynamic diameters of the WCNC, CCNC, and CCNF suspensions in two test media are shown in Fig. 1J-M. The detailed polydispersity index values have been provided in Table S1. As shown in Fig. $1 \mathrm{~J}$ and L, the zeta potential of the CCNC suspensions were more positive as compared to the zeta potential of the WCNC and CCNF suspensions. Moreover, the zeta potential of the CCNF suspensions was more negative than the zeta potential of the WCNC suspensions in the algae medium. As shown in Fig. $1 \mathrm{~K}$ and $\mathrm{M}$, the hydrodynamic diameters of the CCNCs suspensions were significantly lower than those of the WCNC and CCNF suspensions. Moreover, the hydrodynamic diameters of the CCNF suspensions were larger than the diameters of the WCNC suspensions in the algae medium. In general, the assessment of the nanocelluloses from dynamic light scattering measurements is in good agreement with the length estimates from TEM images. The physicochemical analysis indicated that the nanocelluloses studied were well dispensable and stable in the algae and embryo media.

\subsection{Cytotoxicity and oxidative stress induced by nanocelluloses to $S$. obliquus}

Apparent toxicological and biochemical endpoints in S. obliquus as dependent on particle type and exposure concentration were evaluated and compared (Fig. 2). Across the range of the studied concentrations, WCNCs, CCNCs and CCNFs induced no significant growth inhibiting effects on the algal cells (Fig. 2A). Note that CCNFs at the concentration of $10 \mathrm{mg} / \mathrm{L}$ induced an increase in the growth rate compared with the control, implying that CCNFs actually stimulated the algal growth.

As shown in Fig. 2B, the ROS level (\%) of WCNCs at the concentrations ranging from 0.1 to $10 \mathrm{mg} / \mathrm{L}$ showed a significantly higher level than in the control, indicating a significant increase in ROS. Moreover, CCNCs at $10 \mathrm{mg} / \mathrm{L}$ and CCNFs at 1 and $10 \mathrm{mg} / \mathrm{L}$ significantly increased the ROS level. We also used $\mathrm{TAC}_{\mathrm{SM}}$ as an oxidative stress marker to evaluate the non-enzymatic antioxidant activities of $S$. $o b$ liquus. As shown in Fig. 2C, significant increases in the $\mathrm{TAC}_{\mathrm{SM}}$ levels relative to the controls occurred in CCNCs and CCNFs at $10 \mathrm{mg} / \mathrm{L}$. This implies that the $\mathrm{TAC}_{\mathrm{SM}}$ response was associated with the particle type and concentration. These findings point towards the anti-oxidative defense system playing an important role in the response of algal cells to exposure to the nanocelluloses.

The observations by optical microscopy (Fig. 2D-G) and fluorescence microscopy (Fig. 2H-K) provided supportive evidence for the interactions of the nanocelluloses with the algal cells. Compared to the control group, the chlorophyll content in the indicated treatments was obviously reduced (Fig. 2D-G), probably due to the destruction of the chloroplast. The extent of intracellular ROS accumulation reflected the oxidative damage of cells exposed to xenobiotic compounds (Raha and Robinson, 2000). The cells treated with nanocellulose at $10 \mathrm{mg} / \mathrm{L}$ showed stronger vivid green fluorescence, indicating that the nanocelluloses might give rise to oxidative damage in the algae cells.

\subsection{Nanocelluloses induced toxicity and oxidative stress response to $D$. magna}

An overview of survival rates, ROS levels, and $\mathrm{TAC}_{\mathrm{SM}}$ of $D$. magna is provided in Fig. 3. WCNCs, CCNCs and CCNFs were not significantly toxic to D. magna across the range of concentrations studied, as presented in Fig. 3A. Ogonowski et al. (2018) have examined the response of $D$. magna neonates after $48 \mathrm{~h}$ of exposure to CNFs and also observed no mortality.

As shown in Fig. 3B, the ROS levels (\%) of WCNCs at 1 and $10 \mathrm{mg} / \mathrm{L}$, CCNCs at $10 \mathrm{mg} / \mathrm{L}$, and CCNFs at 0.1 and $10 \mathrm{mg} / \mathrm{L}$ were significantly higher than the ROS levels of the control. The TAC $\mathrm{SM}_{\mathrm{SM}}$ levels also significantly increased in case of exposure to WCNCs at $1 \mathrm{mg} / \mathrm{L}$ and to all three nanocelluloses at $10 \mathrm{mg} / \mathrm{L}$ (Fig. 3C).

The results obtained using the optical microscopy (Fig. 3D-G) showed that the three nanocelluloses caused no obvious mechanical damage to D. magna. As shown in Fig. $3 \mathrm{H}-\mathrm{K}$, it was observed that the organisms exposed to the nanocelluloses displayed stronger bright green fluorescence than the control, implying that the nanocelluloses significantly increased the intracellular ROS levels in the daphnids. Furthermore, ROS generated by the nanocelluloses mainly accumulated in the thoracic appendages and end (final) guts of D. magna. Hence it can be concluded that oxidative stress might be a specific controlling mechanism for the toxic effect of the nanocelluloses on $D$. magna.

\subsection{Nanocelluloses induced toxicity and oxidative stress response to $D$.} rerio

Fig. 4 depicts the survival rate, the ROS level, and $\mathrm{TAC}_{\mathrm{SM}}$ of $D$. rerio. Across the range of concentrations studied, WCNCs, CCNCs, and CCNFs induced no significant lethal effects on D. rerio (Fig. 4A). Current studies on aquatic invertebrates and fish have mostly shown low mortality rates when exposed to both CNC (Kovacs et al., 2010) and CNF (Harper 


\section{Colloidal suspension}
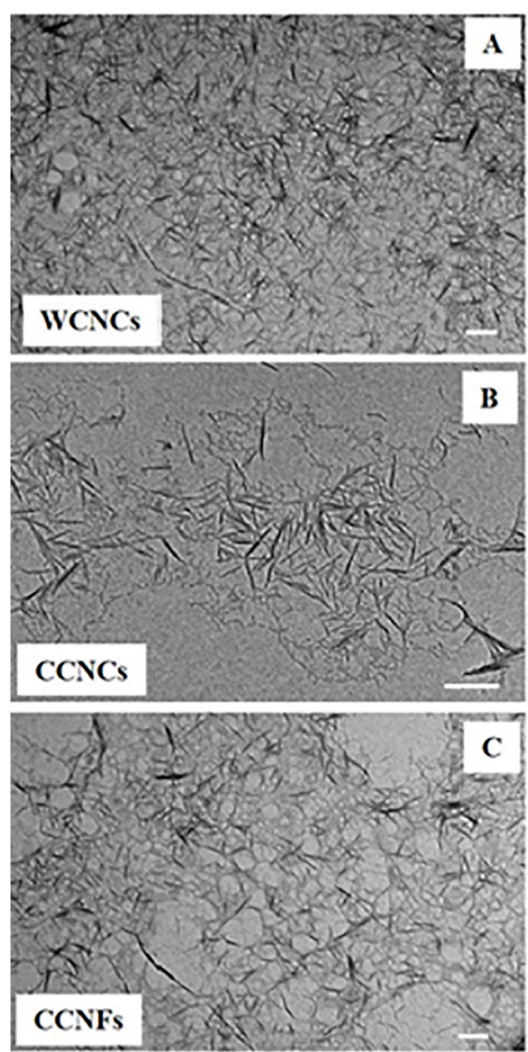

Algae medium
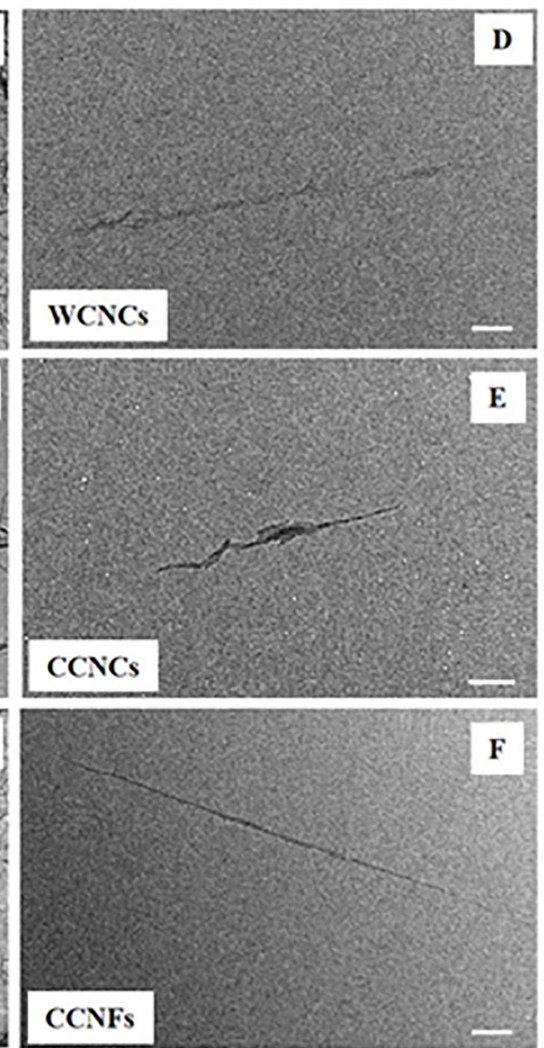

Embryo medium
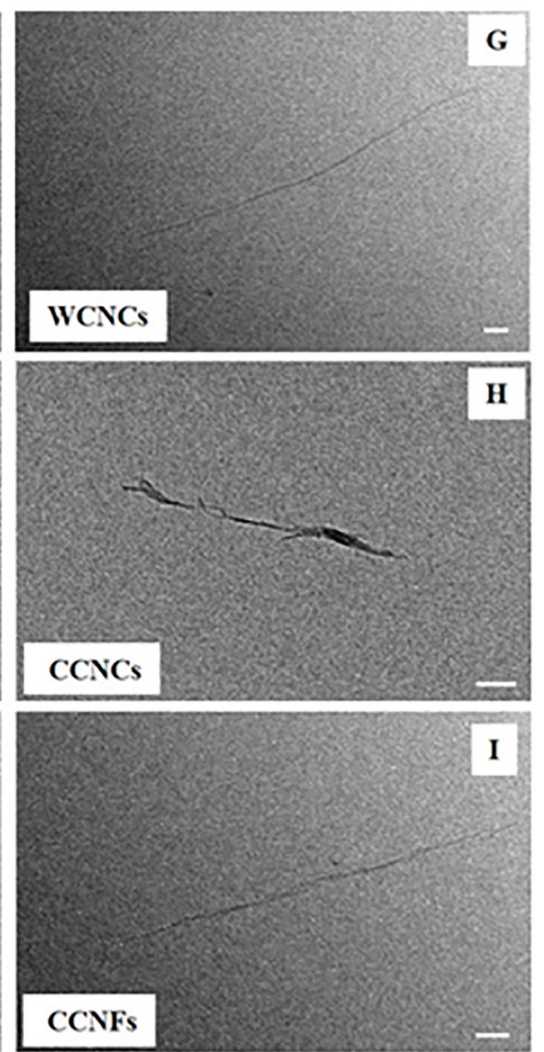

Algae medium

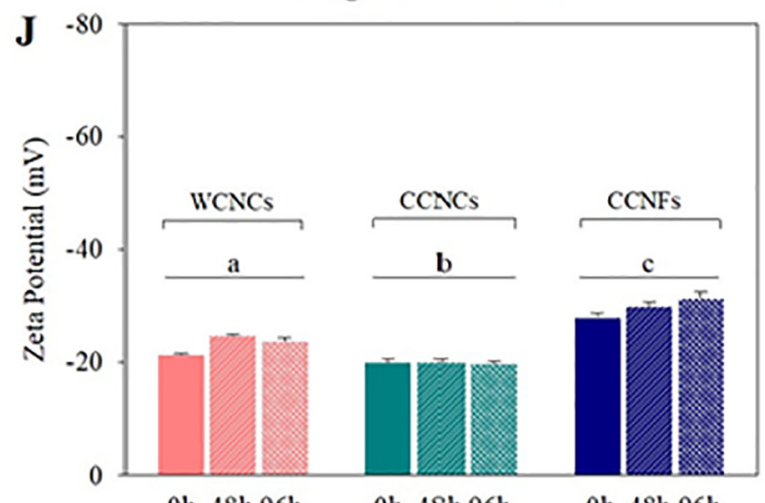

0h 48h $96 \mathrm{~h}$

Oh 48h $96 \mathrm{~h}$

0h 48h $96 \mathrm{~h}$

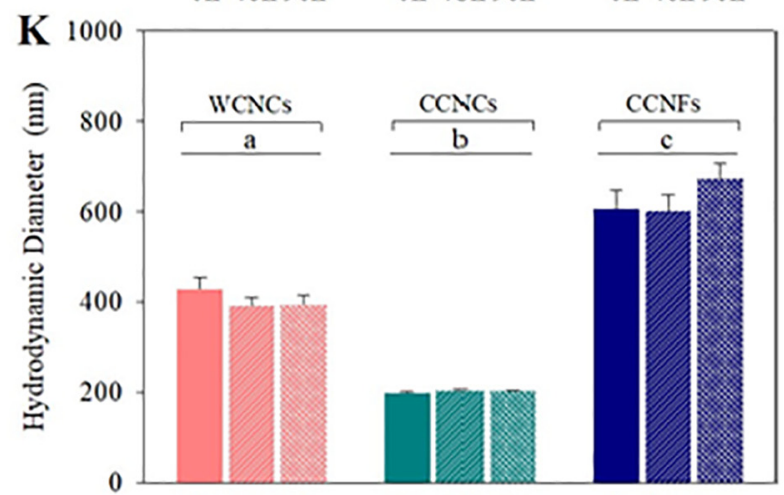

Oh 48h $96 \mathrm{~h}$

0h $48 \mathrm{~h} 96 \mathrm{~h}$

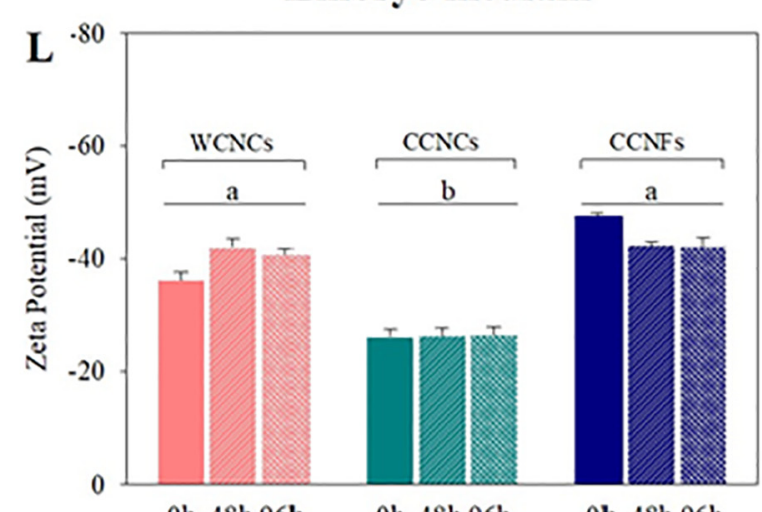

0h 48 h $96 \mathrm{~h}$

0h 48h $96 \mathrm{~h}$

0h 48h $96 \mathrm{~h}$

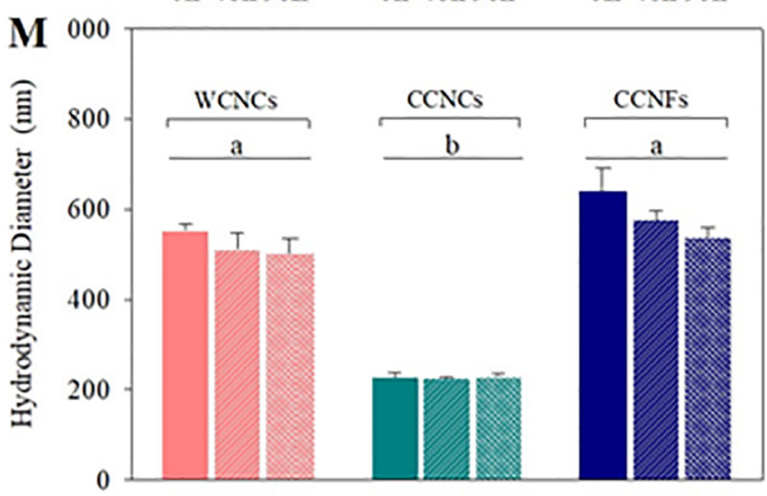

0h $48 \mathrm{~h} 96 \mathrm{~h}$

0h 48h $96 \mathrm{~h}$

0h 48h $96 \mathrm{~h}$

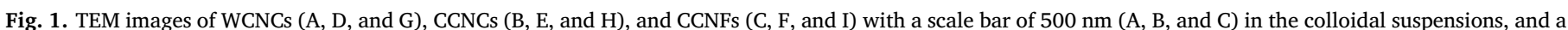

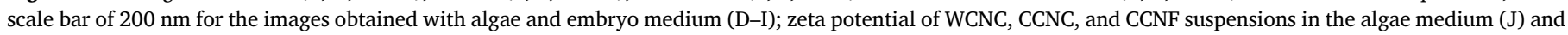

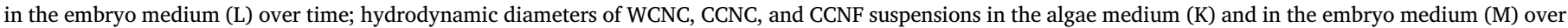
time. Different letters in J-M represent significant differences between the treatments $(p<0.05), n=3$. 

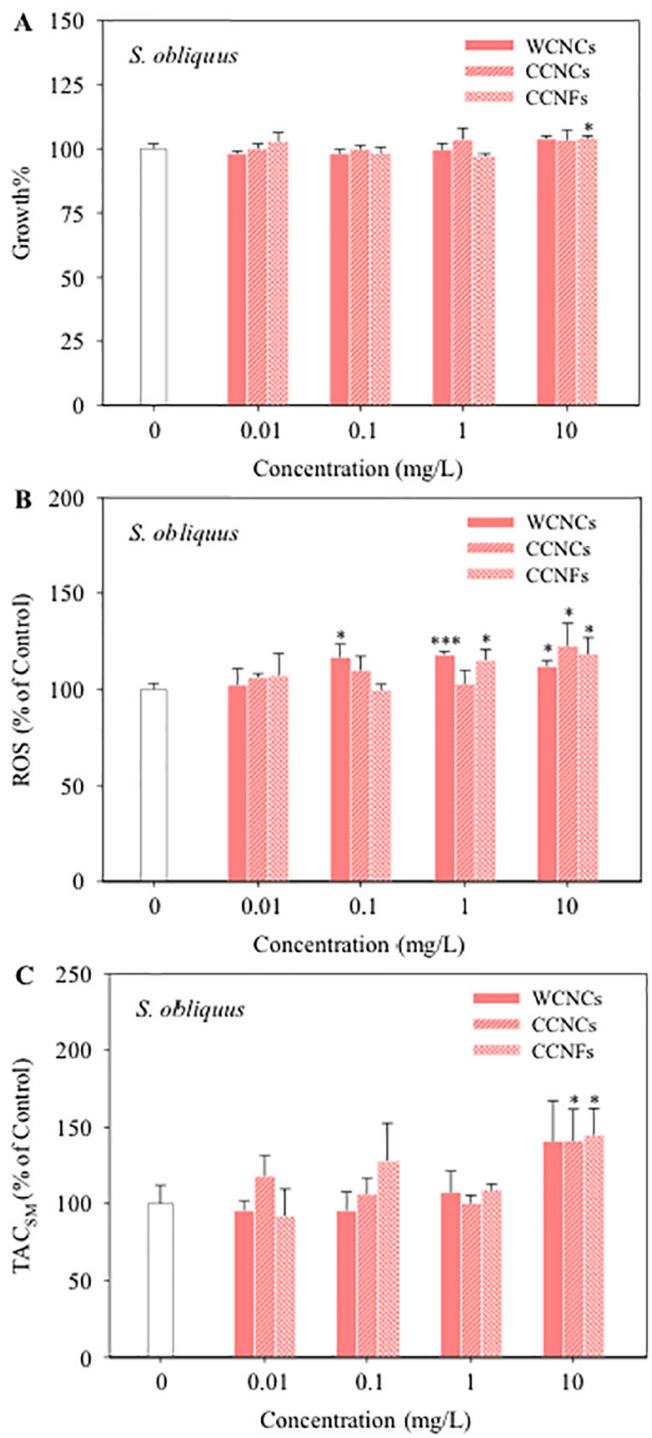
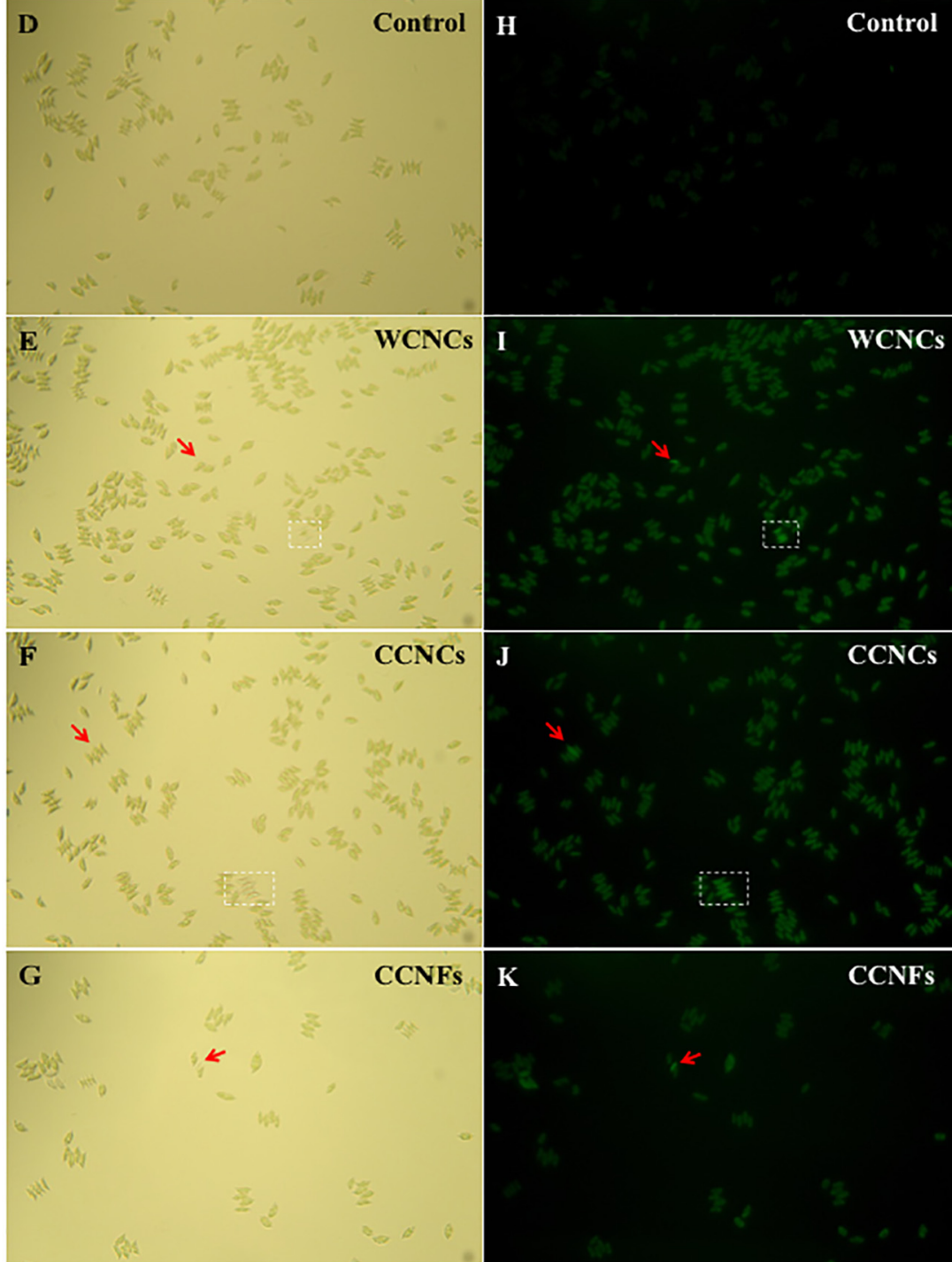

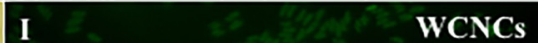

$\mathbf{H}$
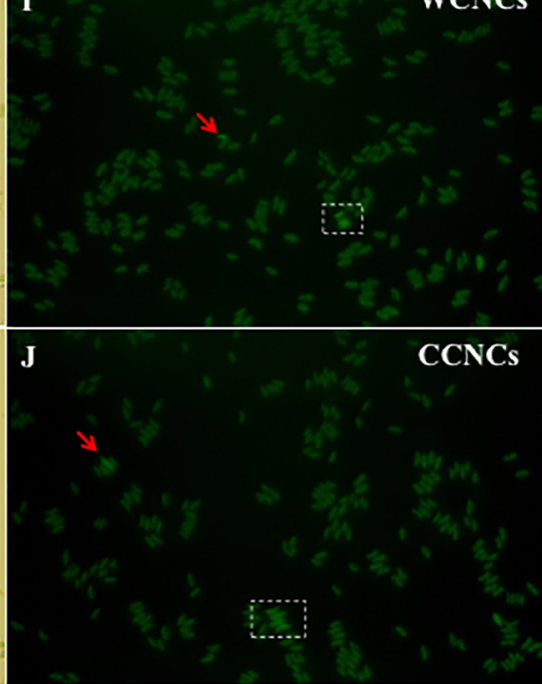

$\mathbf{K}$

CCNFs

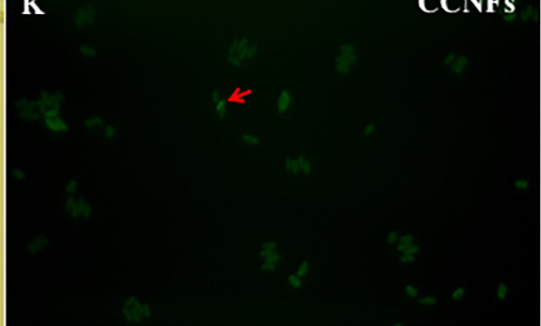

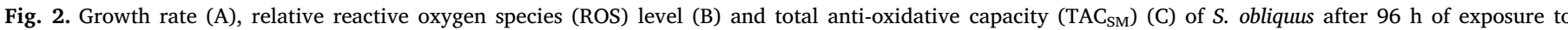

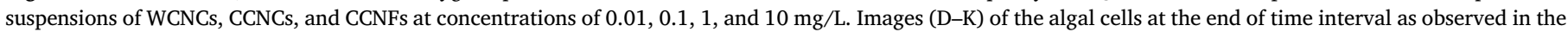

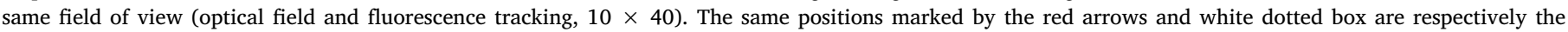
damaged cells and the strong ROS tracking. Statistical significance versus control group: ${ }^{*} p<0.05,{ }^{* *} p<0.01$, and ${ }^{* * *} p<0.001$.

et al., 2016) at relatively high doses $(0.25-1 \mathrm{~g} / \mathrm{L})$.

As shown in Fig. 4B, the ROS levels (\%) induced by WCNCs at $10 \mathrm{mg} / \mathrm{L}$ and CCNCs as well as CCNFs at concentrations ranging from 0.01 to $10 \mathrm{mg} / \mathrm{L}$ were significantly higher than the ROS level in the control, indicating a significant increase in ROS. The TAC $\mathrm{SM}_{\mathrm{SM}}$ levels also significantly increased after exposure to WCNCs at 0.01 and $0.1 \mathrm{mg} / \mathrm{L}$ and CCNFs at concentrations ranging from 0.01 to $10 \mathrm{mg} / \mathrm{L}$ (Fig. 4C). The implication of the tests results are that the first building blocks to create a species sensitivity distribution are prepared. Respecting the species selective sensitivity, our results showed that concentration of the nanocelluloses at which oxidative stress in zebrafish embryos was induced, was the lowest amongst the aquatic organisms of the three trophic levels which we tested.

The images of the optical microscopy (Fig. 4D-G) showed no sublethal impacts on developmental morphology and on teratogenicity toxicological damage after exposure of $D$. rerio to the three nanocelluloses. As shown in Fig. 4H-K, it was observed that the organisms exposed to the nanocelluloses displayed stronger bright green fluorescence than the control, implying that the nanocelluloses significantly increased the intracellular ROS levels in the fish. Furthermore, ROS generated by the nanocelluloses mainly accumulated in the yolk sac regions (as denoted by the red arrows) and the tail part (as denoted by the white dotted boxes). It is evident that induction of oxidative stress might be an important toxicity pathway for the nanocelluloses and occurs upon exposure of aquatic invertebrates to suspensions of nanocelluloses.

\subsection{Comparing ecotoxicological effects induced by nanocellulose to other nanomaterials}

To better estimate the ecological risk of the nanocelluloses, the ecotoxicity data generated within this study were compared to data reported in literature on selected metal-based and carbon-based nanomaterials. The summary of Chen et al. (2015) shows that median-lethal (Effect) concentration $\left(L(E) C_{50}\right.$ ) values for 8 different organisms used within ecotoxicity testing allow for classification of most metal-based nanomaterials within the category "harmful: $10-100 \mathrm{mg} / \mathrm{L} L(E) C_{50}$ ". Likewise, Freixa et al. (2018) concluded that carbon-based nanomaterials (i.e., $\mathrm{C}_{60}$, SWNTs, MWNTs, and graphene) are slightly acute toxic for most aquatic organisms (i.e., algae, crustacean, and fish) (10 mg/ 

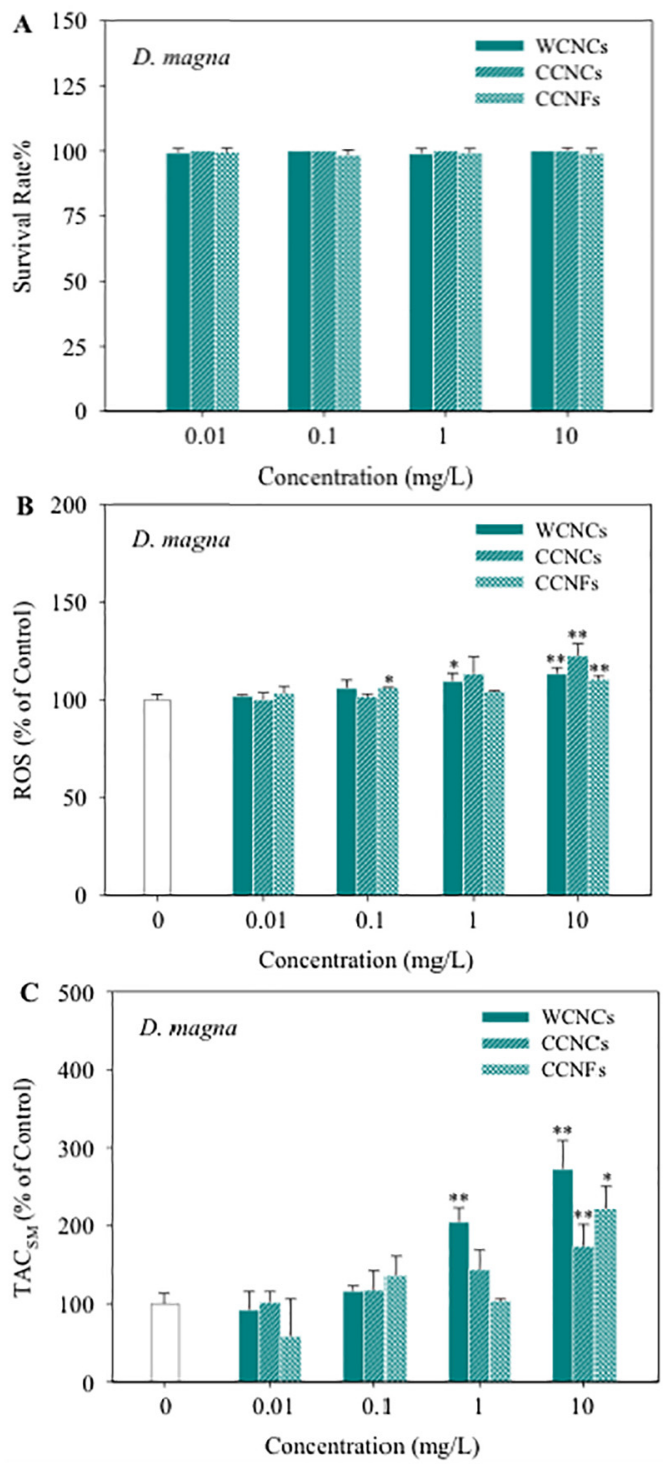
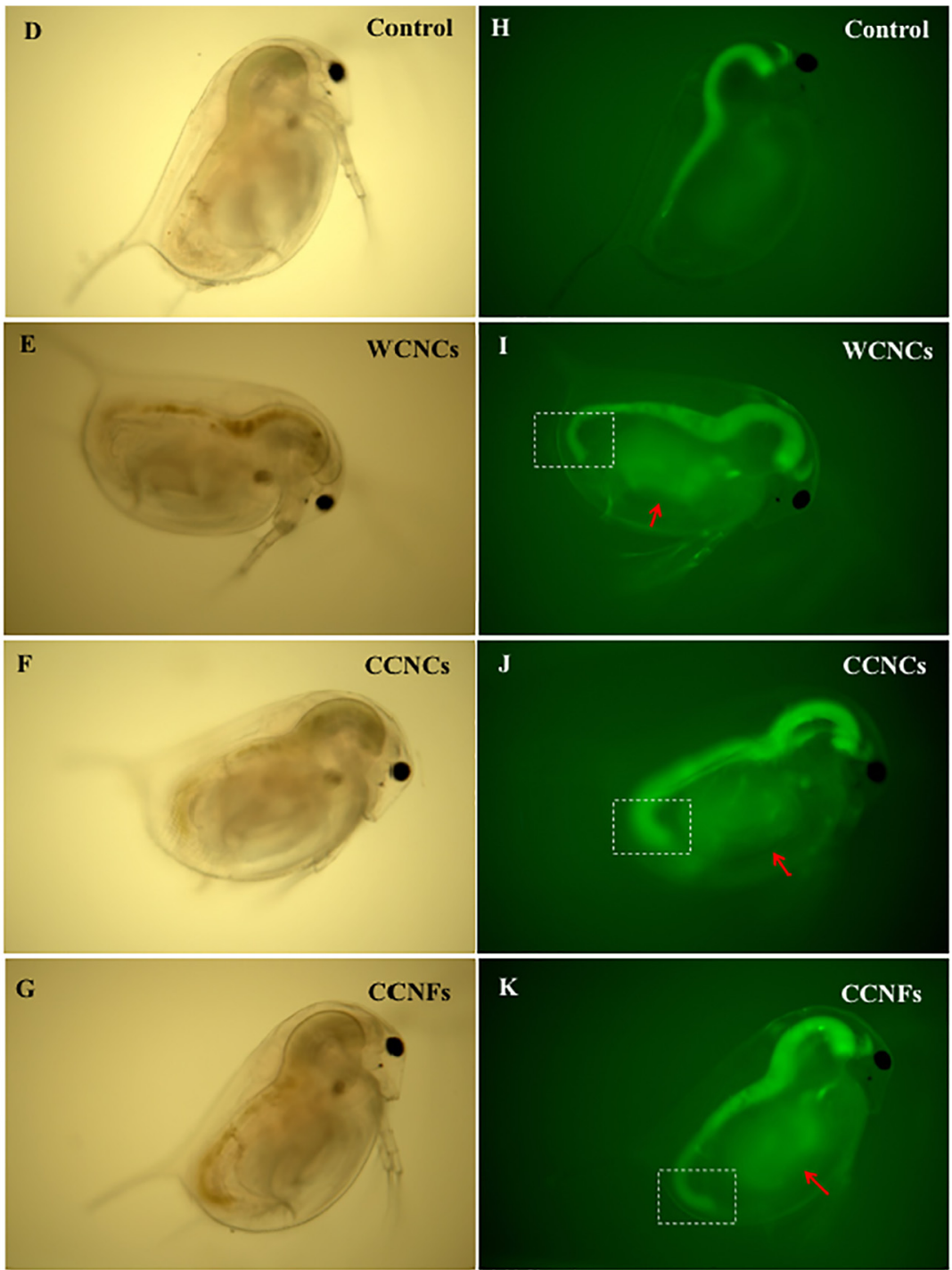

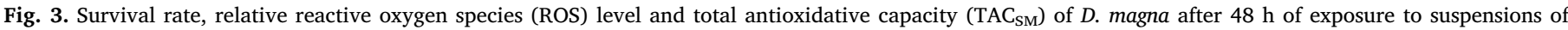

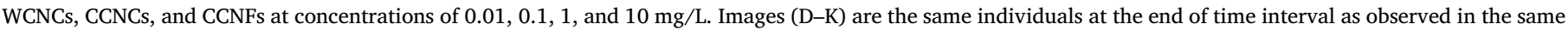

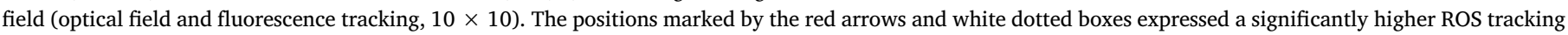
than the control group. Statistical significance versus control group: ${ }^{*} p<0.05,{ }^{* *} p<0.01$, and $* * * p<0.001$.

$\left.\mathrm{L}<E C_{50} \leq 100 \mathrm{mg} / \mathrm{L}\right)$. In contrast, existing reports of acute toxicity induced by nanocellulose materials indicate lack of effects at concentrations below $100 \mathrm{mg} / \mathrm{L}$ (Felix et al., 2016; Harper et al., 2016), not to mention that in some cases the $L(E) C_{50}$ values for organisms of different trophic levels were all higher than $1 \mathrm{~g} / \mathrm{L}$ (Kovacs et al., 2010).

In the present study, for all organisms tested we observed oxidative stress effects appearing at sub-lethal endpoints at relatively low exposure concentrations $(0.01 \mathrm{mg} / \mathrm{L}$ for zebrafish embryo and $0.1 \mathrm{mg} / \mathrm{L}$ for algae and daphnids) irrespective of the nanocellulose material tested. Comparatively, most publications reported the first observable negative effects (such as oxidative stress) of metal-based nanomaterials at around $0.1 \mathrm{mg} / \mathrm{L}$ or even at higher concentrations (Fang et al., 2015; Gonçalves et al., 2018; Lacave et al., 2016; Rodea-Palomares et al., 2011; Valerio-García et al., 2017). For instance, ZnO nanoparticles at a concentration of $0.1 \mathrm{mg} / \mathrm{L}$ increased antioxidative enzyme activities in livers of Carassius auratus after 14-day exposure (Benavides et al., 2016). A concentration of $5 \mathrm{mg} / \mathrm{L}$ of $\mathrm{TiO}_{2}$ nanoparticles significantly increased the ROS level of Nitzschia closterium (Xia et al., 2015). A concentration of $12.5 \mathrm{mg} / \mathrm{L} \mathrm{CeO}_{2}$ nanoparticles did not cause mortality of Corophium volutator but induced sub-lethal effects through oxidative stress (Dogra et al., 2016). Our findings suggest that although the aquatic toxicity of nanocellulose materials was lower than the toxicity of metal-based nanomaterials, nanocellulose materials are prone to induce oxidative stress at low exposure levels.

Many studies also found that carbon-based nanomaterials induced oxidative stress at concentrations $\geq 0.01 \mathrm{mg} / \mathrm{L}$ (Cano et al., 2017; Freixa et al., 2018; Hu et al., 2015; Schwab et al., 2011; Tao et al., 2015). For example, the increase of ROS levels and the reduction of relative activity of superoxide dismutase enzyme was observed in algal cells after $96 \mathrm{~h}$ exposure to $0.01-10 \mathrm{mg} / \mathrm{L}$ carboxyl single-walled carbon nanotubes (Hu et al., 2015). In general, ROS induction in the aquatic organisms of different trophic levels was observed at relatively low exposure levels of nanocellulose. As far as we know, this is the first study that explores the mechanisms of toxicity of nanocellulose in aquatic organisms. And indeed although oxidative stress is not a surprising endpoint to nanomaterials exposure, our results showed that even though nanocellulose is of biogenic origin, still oxidative stress occurs. Therefore, it is needed to understand the meaning of ROS induction in terms of ecosystem-relevant endpoints. 

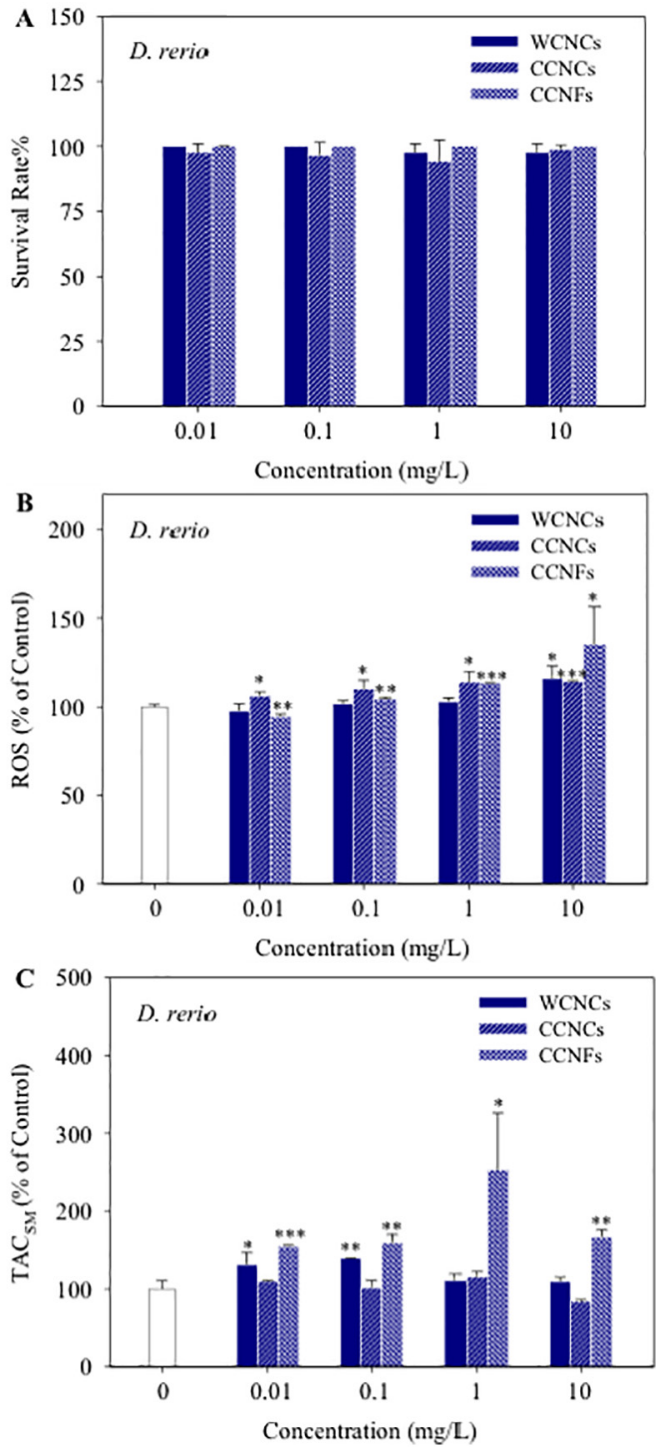
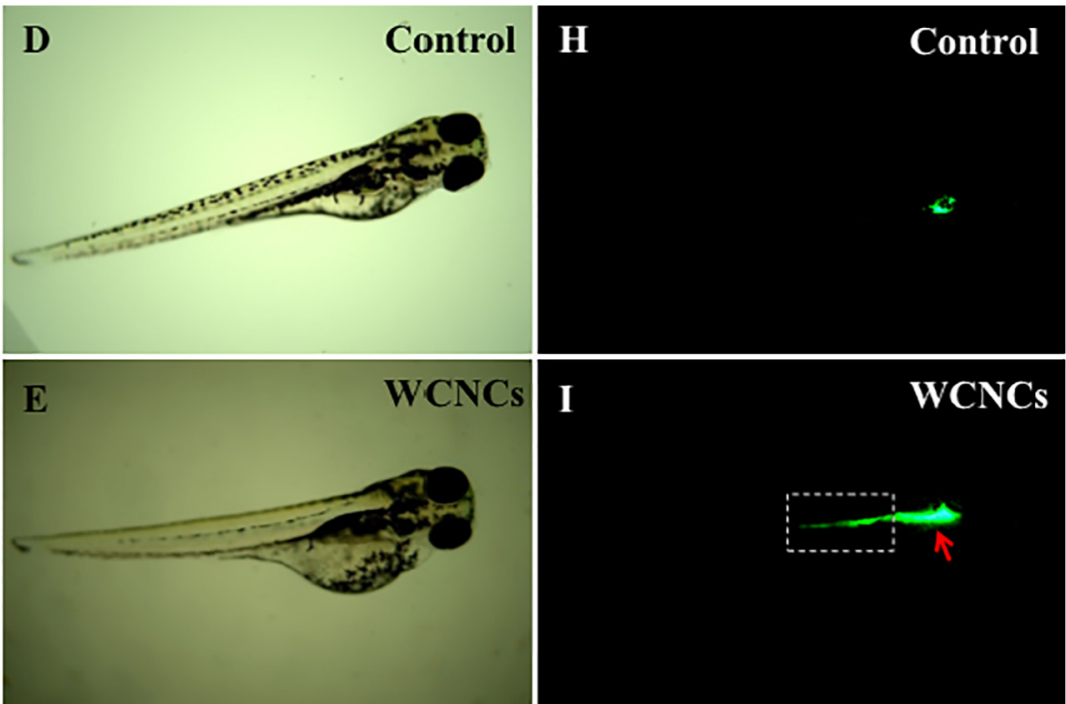

WCNCs
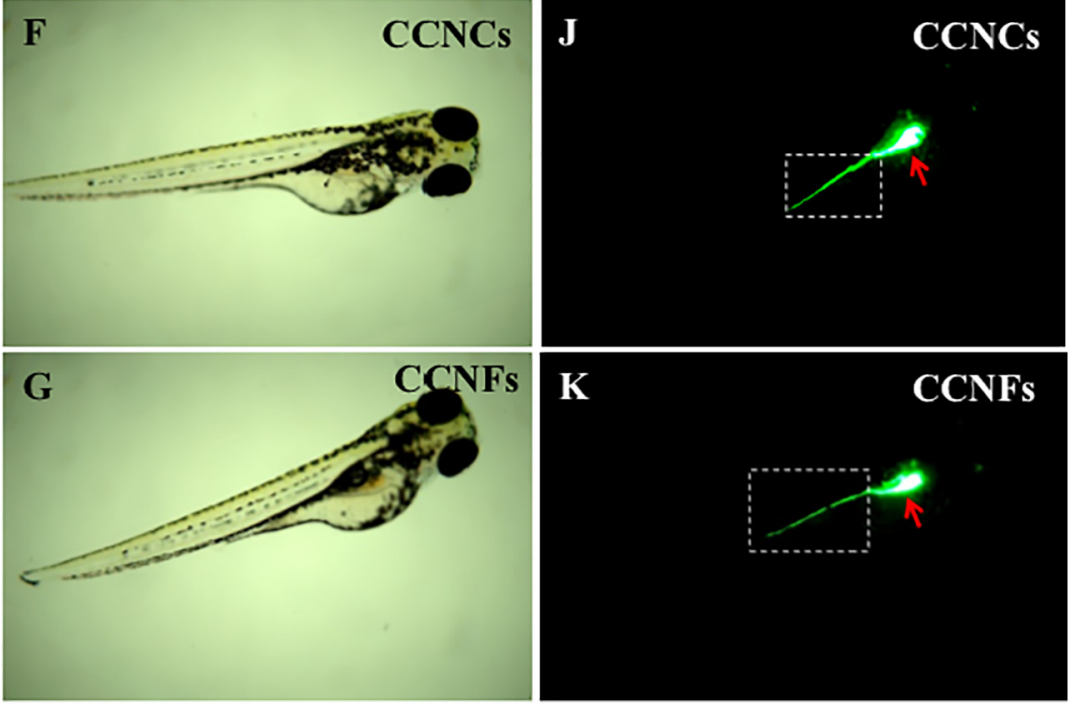

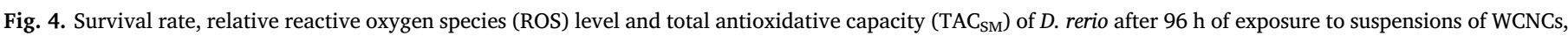

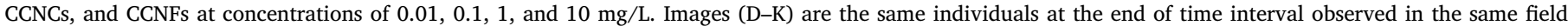

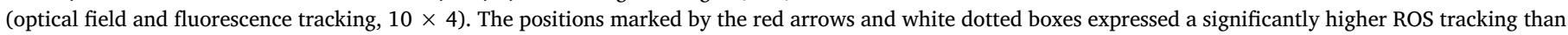
the control group. Statistical significance versus control group: ${ }^{*} p<0.05$, ${ }^{* *} p<0.01$, and ${ }^{* * *} p<0.001$.

\section{Conclusions}

Although presumed environmental-friendly and safe, we observed that the nanocellulose materials induced oxidative stress in aquatic organisms of three different trophic levels at concentrations as low as $0.01 \mathrm{mg} / \mathrm{L}$. The particle-induced oxidative stress was mainly associated with the nanocellulose form, morphology, and exposure concentration of the nanocelluloses. These findings are counterintuitive when compared to societal expectations of naturally occurring cellulose fibers to be biodegradable and non-toxic. The findings of this study, therefore, emphasize the importance of evaluating the ecotoxicological impacts (both exposure and effects) of the accelerating use of nanocellulose materials for ever-growing human production needs.

\section{CRediT authorship contribution statement}

Zhuang Wang: Conceptualization, Methodology, Resources, Investigation, Data curation, Formal analysis, Writing - original draft, Visualization, Funding acquisition, Project administration. Lan Song: Writing - review \& editing, Funding acquisition, Project administration.
Nan Ye: Investigation, Writing - review \& editing. Qi Yu: Validation, Writing - review \& editing. Yujia Zhai: Formal analysis, Writing - review \& editing. Fan Zhang: Visualization, Writing - review \& editing. Martina G. Vijver: Writing - review \& editing, Supervision, Funding acquisition, Project administration. Willie J.G.M. Peijnenburg: Writing - review \& editing, Supervision, Funding acquisition, Project administration.

\section{Declaration of competing interest}

The authors declare that they have no known competing financial interests or personal relationships that could have appeared to influence the work reported in this paper.

\section{Acknowledgments}

The research described in this work was supported by the European Union's Horizon 2020 research and innovation programme "PATROLS" (grant number: 760813). The work was also sponsored by the National Natural Science Foundation of China (grant number: 31971522), the 
Natural Science Foundation of Jiangsu Province (grant number: BK20191403), Guangdong Provincial Key Laboratory of Soil and Groundwater Pollution Control (grant number: 2017B030301012), and State Environmental Protection Key Laboratory of Integrated Surface Water-Groundwater Pollution Control.

\section{References}

Antonkiewicz, J., Baran, A., Pelka, R., Wisła-Świder, A., Nowak, E., Konieczka, P., 2019. A mixture of cellulose production waste with municipal sewage as new material for an ecological management of wastes. Ecotoxicol. Environ. Saf. 169, 607-614.

Benavides, M., Fernández-Lodeiro, J., Coelho, P., Lodeiro, C., Diniz, M.S., 2016. Single and combined effects of aluminum $\left(\mathrm{Al}_{2} \mathrm{O}_{3}\right)$ and zinc $(\mathrm{ZnO})$ oxide nanoparticles in freshwater fish, Carassius auratus. Environ. Sci. Pollut. Res. 23 (24), 24578-24591.

Cano, A.M., Maul, J.D., Saed, M., Shah, S.A., Green, M.J., Canas-Carrell, J.E., 2017. Bioaccumulation, stress, and swimming impairment in Daphnia magna exposed to multiwalled carbon nanotubes, graphene, and graphene oxide. Environ. Toxicol. Chem. 36 (8), 2199-2204.

Chen, G., Vijver, M.G., Peijnenburg, W.J.G.M., 2015. Summary and analysis of the currently existing literature data on metal-based nanoparticles published for selected aquatic organisms: applicability for toxicity prediction by (Q)SARs. ATLA Altern. Lab. Anim. 43 (4), 221-240.

Chen, G., Peijnenburg, W.J.G.M., Xiao, Y., Vijver, M.G., 2018. Developing species sensitivity distributions for metallic nanomaterials considering the characteristics of nanomaterials, experimental conditions, and different types of endpoints. Food Chem. Toxicol. 112, 563-570.

Cimbaluk, G.V., Ramsdorf, W.A., Perussolo, M.C., Santos, H.K.F., Da Silva De Assis, H.C., Schnitzler, M.C., Schnitzler, D.C., Carneiro, P.G., Cestari, M.M., 2018. Evaluation of multiwalled carbon nanotubes toxicity in two fish species. Ecotoxicol. Environ. Saf. 150, 215-223.

Cordeiro, M.F., Girardi, F.A., Gonçalves, C.O.F., Peixoto, C.S., Dal Bosco, L., Sahoo, S.K., Santos, A.P., Fantini, C., Bruch, G.E., Horn, A.P., Barros, D.M., 2018. Toxicological assessment of PEGylated single-walled carbon nanotubes in early developing zebrafish. Toxicol. Appl. Pharmacol. 347, 54-59.

de Figueirêdo, M.C.B., de Freitas Rosa, M., Lie Ugaya, C.M., de Souza Filho, M.D.S.M., da Silva Braid, A.C.C., de Melo, L.F.L., 2012. Life cycle assessment of cellulose nanowhiskers. J. Clean. Prod. 35, 130-139.

De Marchi, L., Pretti, C., Gabriel, B., Marques, P.A.A.P., Freitas, R., Neto, V., 2018. An overview of graphene materials: properties, applications and toxicity on aquatic environments. Sci. Total Environ. 631-632, 1440-1456.

Deepa, B., Abraham, E., Cherian, B.M., Bismarck, A., Blaker, J.J., Pothan, L.A., Leao, A.L., de Souza, S.F., Kottaisamy, M., 2011. Structure, morphology and thermal characteristics of banana nano fibers obtained by steam explosion. Bioresour. Technol. 102(2), 1988-1997.

Dogra, Y., Arkill, K.P., Elgy, C., Stolpe, B., Lead, J., Valsami-Jones, E., Tyler, C.R., Galloway, T.S., 2016. Cerium oxide nanoparticles induce oxidative stress in the sediment-dwelling amphipod Corophium volutator. Nanotoxicology. 10 (4), 480-487.

Du, L., Arnholt, K., Ripp, S., Sayler, G., Wang, S., Liang, C., Wang, J., Zhuang, J., 2015. Biological toxicity of cellulose nanocrystals (CNCs) against the luxCDABE-based bioluminescent bioreporter Escherichia coli 652T7. Ecotoxicology. 24 (10), 2049-2053.

Eichhorn, S.J., Dufresne, A., Aranguren, M., Marcovich, N.E., Capadona, J.R., Rowan, S.J., Weder, C., Thielemans, W., Roman, M., Renneckar, S., Gindl, W., Veigel, S., Keckes, J., Yano, H., Abe, K., Nogi, M., Nakagaito, A.N., Mangalam, A., Simonsen, J., Benight, A.S., Bismarck, A., Berglund, L.A., Peijs, T., 2010. Review: current international research into cellulose nanofibres and nanocomposites. J. Mater. Sci. 45, $1-33$.

Fang, T., Yu, L.P., Zhang, W.C., Bao, S.P., 2015. Effects of humic acid and ionic strength on $\mathrm{TiO}_{2}$ nanoparticles sublethal toxicity to zebrafish. Ecotoxicology. 24 (10), 2054-2066.

Farcas, M.T., Kisin, E.R., Menas, A.L., Gutkin, D.W., Star, A., Reiner, R.S., Yanamala, N., Savolainen, K., Shvedova, A.A., 2016. Pulmonary exposure to cellulose nanocrystals caused deleterious effects to reproductive system in male mice. J. Toxicol. Environ. Health A. 79 (21), 984-997.

Felix, L.C., Ede, J.D., Snell, D.A., Oliveira, T.M., Martinez-Rubi, Y., Simard, B., Luong, J.H.T., Goss, G.G., 2016. Physicochemical properties of functionalized carbon-based nanomaterials and their toxicity to fishes. Carbon 104, 78-89.

Freixa, A., Acuña, V., Sanchís, J., Farré, M., Barceló, D., Sabater, S., 2018. Ecotoxicological effects of carbon based nanomaterials in aquatic organisms. Sci. Total Environ. 619-620, 328-337.

Ghobadian, M., Nabiuni, M., Parivar, K., Fathi, M., Pazooki, J., 2015. Toxic effects of magnesium oxide nanoparticles on early developmental and larval stages of zebrafish (Danio rerio). Ecotoxicol. Environ. Saf. 122, 260-267.

Gonçalves, R.A., de Oliveira Franco Rossetto, A.L., Nogueira, D.J., Vicentini, D.S., Matias, W.G., 2018. Comparative assessment of toxicity of $\mathrm{ZnO}$ and amine-functionalized $\mathrm{ZnO}$ nanorods toward Daphnia magna in acute and chronic multigenerational tests. Aquat. Toxicol. 197, 32-40.

Harper, B.J., Clendaniel, A., Sinche, F., Way, D., Hughes, M., Schardt, J., Simonsen, J. Stefaniak, A.B., Harper, S.L., 2016. Impacts of chemical modification on the toxicity of diverse nanocellulose materials to developing zebrafish. Cellulose (Lond). 23 (3), 1763-1775.
Hemraz, U.D., Campbell, K.A., Burdick, J.S., Ckless, K., Boluk, Y., Sunasee, R., 2015 Cationic poly(2-aminoethylmethacrylate) and poly(N-(2-aminoethylmethacrylamide)) modified cellulose nanocrystals: synthesis, characterization, and cytotoxicity. Biomacromolecules. 16 (1), 319-325.

Hu, X., Ouyang, S., Mu, L., An, J., Zhou, Q., 2015. Effects of graphene oxide and oxidized carbon nanotubes on the cellular division, microstructure, uptake, oxidative stress, and metabolic profiles. Environ. Sci. Technol. 49 (18), 10825-10833.

Islam, M.T., Alam, M.M., Patrucco, A., Montarsolo, A., Zoccola, M., 2014. Preparation of nanocellulose: a review. AATCC. J. Res. 1 (5), 17-23.

Ivask, A., Juganson, K., Bondarenko, O., Mortimer, M., Aruoja, V., Kasemets, K., Blinova, I., Heinlaan, M., Slaveykova, V., Kahru, A., 2014. Mechanisms of toxic action of Ag, $\mathrm{ZnO}$ and $\mathrm{CuO}$ nanoparticles to selected ecotoxicological test organisms and mammalian cells in vitro: a comparative review. Nanotoxicology. 8 (Suppl. 1), 57-71.

Kargarzadeh, H., Mariano, M., Gopakumar, D., Ahmad, I., Thomas, S., Dufresne, A., Huang, J., Lin, N., 2018. Advances in cellulose nanomaterials. Cellulose. 25 (4), 2151-2189.

Klemm, D., Kramer, F., Moritz, S., Lindström, T., Ankerfors, M., Gray, D., Dorris, A., 2011. Nanocelluloses: a new family of nature-based materials. Angew. Chem. Int. Ed. Engl. 50 (24), 5438-5466.

Kovacs, T., Naish, V., O'Connor, B., Blaise, C., Gagné, F., Hall, L., Trudeau, V., Martel, P., 2010. An ecotoxicological characterization of nanocrystalline cellulose (NCC). Nanotoxicology. 4 (3), 255-270.

Lacave, J.M., Retuerto, A., Vicario-Parés, U., Gilliland, D., Oron, M., Cajaraville, M.P., Orbea, A., 2016. Effects of metal-bearing nanoparticles (Ag, Au, CdS, $\mathrm{ZnO}, \mathrm{SiO}_{2}$ ) on developing zebrafish embryos. Nanotechnology. 27 (32), 325102.

OECD, 2004. Guideline for Testing of Chemicals. Daphnia sp., Acute Immobilization Test. No. 202. Organisation for Economic Co-operation and Development, Paris.

OECD, 2006. Guidelines for Testing of Chemicals. Freshwater Alga and Cyanobacteria, Growth Inhibition Test. No. 201. Organisation for Economic Co-operation and Development, Paris.

OECD, 2013. Guideline for Testing of Chemicals. Fish Embryo Acute Toxicity (FET) Test. No. 236. Organisation for Economic Co-operation and Development, Paris.

Ogonowski, M., Edlund, U., Gorokhova, E., Linde, M., Ek, K., Liewenborg, B., Könnecke, O., Navarro, J.R.G., Breitholtz, M., 2018. Multi-level toxicity assessment of engineered cellulose nanofibrils in Daphnia magna. Nanotoxicology. 12 (6), 509-521.

Raha, S., Robinson, B.H., 2000. Mitochondria, oxygen free radicals, disease and ageing. Trends Biochem. Sci. 25 (10), 502-508.

Rodea-Palomares, I., Boltes, K., Fernández-Piñas, F., Leganés, F., García-Calvo, E. Santiago, J., Rosal, R., 2011. Physicochemical characterization and ecotoxicological assessment of $\mathrm{CeO}_{2}$ nanoparticles using two aquatic microorganisms. Toxicol. Sci. 119 (1), 135-145.

Salehpour, S., Jonoobi, M., Ahmadzadeh, M., Siracusa, V., Rafieian, F., Oksman, K., 2018. Biodegradation and ecotoxicological impact of cellulose nanocomposites in municipal solid waste composting. Int. J. Biol. Macromol. 111, 264-270.

Schwab, F., Bucheli, T.D., Lukhele, L.P., Magrez, A., Nowack, B., Sigg, L., Knauer, K., 2011. Are carbon nanotube effects on green algae caused by shading and agglomeration? Environ. Sci. Technol. 45 (14), 6136-6144.

Tao, X., Yu, Y., Fortner, J.D., He, Y., Chen, Y., Hughes, J.B., 2015. Effects of aqueous stable fullerene nanocrystal $\left(\mathrm{nC}_{60}\right)$ on Scenedesmus obliquus: evaluation of the sublethal photosynthetic responses and inhibition mechanism. Chemosphere. 122, 162-167.

Thakkar, M., Mitra, S., Wei, L., 2016. Effect on growth, photosynthesis, and oxidative stress of single walled carbon nanotubes exposure to marine alga Dunaliella tertiolecta. J. Nanomater. 2016, 8380491.

Trache, D., Hussin, M.H., Haafiz, M.K., Thakur, V.K., 2017. Recent progress in cellulose nanocrystals: sources and production. Nanoscale. 9 (5), 1763-1786.

Valerio-García, R.C., Carbajal-Hernández, A.L., Martínez-Ruíz, E.B., Jarquín-Díaz, V.H., Haro-Pérez, C., Martínez-Jerónimo, F., 2017. Exposure to silver nanoparticles produces oxidative stress and affects macromolecular and metabolic biomarkers in the goodeid fish Chapalichthys pardalis. Sci. Total Environ. 583, 308-318.

Vartiainen, J., Pöhler, T., Sirola, K., Pylkkänen, L., Alenius, H., Hokkinen, J., Tapper, U., Lahtinen, P., Kapanen, A., Putkisto, K., Hiekkataipale, P., Eronen, P., Ruokolainen, J., Laukkanen, A., 2011. Health and environmental safety aspects of friction grinding and spray drying of microfibrillated cellulose. Cellulose 18, 775-786.

Wang, S., Wang, Z., Chen, M., Fang, H., Wang, D., 2017. Co-exposure of freshwater microalgae to tetrabromobisphenol A and sulfadiazine: oxidative stress biomarker responses and joint toxicity prediction. Bull. Environ. Contam. Toxicol. 99 (4), 438-444.

Wei, L., Thakkar, M., Chen, Y., Ntim, S.A., Mitra, S., Zhang, X., 2010. Cytotoxicity effects of water dispersible oxidized multiwalled carbon nanotubes on marine alga, Dunaliella tertiolecta. Aquat. Toxicol. 100 (2), 194-201.

Xia, B., Chen, B., Sun, X., Qu, K., Ma, F., Du, M., 2015. Interaction of $\mathrm{TiO}_{2}$ nanoparticles with the marine microalga Nitzschia closterium: growth inhibition, oxidative stress and internalization. Sci. Total Environ. 508, 525-533.

Xie, F., Koziar, S.A., Lampi, M.A., Dixon, D.G., Warren, N.P., Borgmann, U., Huang, X.D., Greenberg, B.M., 2006. Assessment of the toxicity of mixtures of copper, 9,10-phenanthrenequinone, and phenanthrene to Daphnia magna: evidence for a reactive oxygen mechanism. Environ. Toxicol. Chem. 25 (2), 613-622.

Yanamala, N., Farcas, M.T., Hatfield, M.K., Kisin, E.R., Kagan, V.E., Geraci, C.L., Shvedova, A.A., 2014. In vivo evaluation of the pulmonary toxicity of cellulose nanocrystals: a renewable and sustainable nanomaterial of the future. ACS Sustain. Chem. Eng. 2 (7), 1691-1698. 